\title{
OPCML Exerts Antitumor Effects in Cholangiocarcinoma via AXL/STAT3 Inactivation and Rho GTPase Down-regulation
}

\author{
RICUPHAN KHAMKO ${ }^{1,2}$, JUREERUT DADUANG ${ }^{2}$, CHATRI SETTASATIAN ${ }^{3}$ and TEMDUANG LIMPAIBOON ${ }^{2,4}$ \\ ${ }^{1}$ Biomedical Science Program, Graduate School, Khon Kaen University, Khon Kaen, Thailand; \\ ${ }^{2}$ Centre for Research and Development of Medical Diagnostic Laboratories, \\ Faculty of Associated Medical Sciences, Khon Kaen University, Khon Kaen, Thailand; \\ ${ }^{3}$ Department of Pathology, Faculty of Medicine, Khon Kaen University, Khon Kaen, Thailand; \\ ${ }^{4}$ Cholangiocarcinoma Research Institute, Faculty of Medicine, Khon Kaen University, Khon Kaen, Thailand
}

\begin{abstract}
Background/Aim: Opioid-binding protein/cell adhesion molecule-like (OPCML) plays a crucial role in the suppression of tumor progression in several cancer types. Nevertheless, the association between OPCML functions and cholangiocarcinoma (CCA) progression remains unknown. We aimed to investigate biological functions of OPCML and related signaling pathways in CCA cell lines. Materials and Methods: Methylation status and ectopic expression of OPCML were determined in CCA cell lines using methylationspecific polymerase chain reaction and pcDNA3.1+/C(K)DYK-OPCML, respectively. Cell proliferation, migration and invasion were investigated. Results: OPCML was found to be epigenetically silenced by DNA methylation. Ectopic expression of OPCML inhibited CCA proliferation by inducing apoptosis via AXL receptor tyrosine kinase/signal transducer and activator of transcription 3 (AXL/STAT3) inactivation. It also suppressed cell migration and invasion via downregulation of Rho GTPases, ras homolog family member $A$ (RHOA), Rac family small GTPase 1 (RAC1) and cell division cycle 42 (CDC42). Conclusion: We are the first to unravel the antitumor effects and the related signaling pathways of OPCML in CCA. The loss of OPCML expression due to promoter hypermethylation can cause a decrease in cell death but increase in cell migration and invasion, which may at least in part contribute to CCA progression.
\end{abstract}

This article is freely accessible online.

Correspondence to: Temduang Limpaiboon, Centre for Research and Development of Medical Diagnostic Laboratories, Faculty of Associated Medical Sciences, Khon Kaen University, Khon Kaen 40002, Thailand. E-mail: temduang@kku.ac.th

Key Words: OPCML, methylation, AXL/STAT3 signaling, RHOA/RAC1/CDC42.
Cholangiocarcinoma (CCA) is an epithelial cancer of bile ducts (1), which is a rare cancer worldwide (2). However, it is the most common in the Northeastern region of Thailand, with the highest incidence approximately 85 per 100,000 (3). CCA is characterized by poor prognosis, and usually diagnosed at a late stage (4). Hence, the study of new molecules to be used as biomarkers is vital for early diagnosis. A previous study by Sriraksa et al. reported the methylation frequency of $26 \mathrm{CpG}$-island loci in CCA, of which opioidbinding protein/cell adhesion molecule like (OPCML) was the most frequently methylated locus along with low or no expression (5), suggesting the effect of DNA methylation on gene expression. In addition, Amonpisutt et al. also reported the significantly high level of methylation of $O P C M L$ in CCA when compared to adjacent normal tissues. They suggested that DNA methylation level of $O P C M L$ might be used as a potential diagnostic biomarker for CCA (6).

OPCML is a glycosyl phosphatidylinositol-anchored cell adhesion-like molecule. It normally acts as a cell adhesion molecule and negative regulator, and is associated with signal transduction by regulating a set of receptor tyrosine kinases including EPH receptor A2 (EPHA2), fibroblast growth factor receptor 1 (FGFR1), FGFR3, erb-b2 receptor tyrosine kinase 2 (HER2) and HER4 in normal ovarian epithelial cells (7). Moreover, OPCML acts as a tumor suppressor and is frequently inactivated by promoter hypermethylation, resulting in gene silencing in multiple cancer types, including invasive cervical carcinoma (8), bladder carcinoma (9), colorectal cancer (10), epithelial ovarian cancer (11), and CCA (5). Many studies have demonstrated the important roles of OPCML in the suppression of tumor progression in various types of human cancer $(7,10,12-14)$. Nonetheless, the relationship between its biological roles and CCA progression remains unknown. Herein, we explored the involvement of OPCML methylation status and its endogenous expression in CCA cell lines. We also investigated the biological functions, 
Table I. List of primer sequences.

\begin{tabular}{|c|c|c|c|}
\hline Primer & & Sequence $\left(5^{\prime} \rightarrow 3^{\prime}\right)$ & Product size (bp) \\
\hline \multicolumn{4}{|l|}{ MSP } \\
\hline \multicolumn{4}{|l|}{ OPCML } \\
\hline \multirow[t]{2}{*}{ Methylated } & Forward & GCGCG GTGCGGGTTTATTTTC & 136 \\
\hline & Reverse & TCCCGATACCGCCTCGAAACGAACG & \\
\hline \multirow[t]{2}{*}{ Unmethylated } & Forward & GTGTGGTGTGGGTTTATTTTT & 136 \\
\hline & Reverse & TCCCAATACCACCTCAAAACAAACA & \\
\hline \multicolumn{4}{|l|}{ RT-PCR } \\
\hline \multirow[t]{2}{*}{$O P C M L$} & Forward & GGTTACCCGGTCATCTATGG & 124 \\
\hline & Reverse & CCTTGTACCCACAGGAGTGC & \\
\hline \multirow[t]{2}{*}{ GAPDH } & Forward & AGAGGCAGGGATGATGTTCT & 243 \\
\hline & Reverse & ATGTTCGTCATGGGTGTGAA & \\
\hline
\end{tabular}

GAPDH: Glyceraldehyde 3-phosphate dehydrogenase; MSP: methylation-specific polymerase chain reaction; $O P C M L$ : opioid-binding protein/cell adhesion molecule like; RT-PCR: reverse transcription polymerase chain reaction.

as well as the related signaling pathways, when OPCML was ectopically expressed.

\section{Materials and Methods}

Cell lines and culture. The CCA cell lines (KKU-M213A, KKUM055, and KKU-100) were established and kindly provided by the Cholangiocarcinoma Research Institute, Khon Kaen University, Thailand. KKU-M055 and KKU-M213A were cultured in Dulbecco's modified Eagle's medium, whereas KKU-100 was cultured in Ham's F-12 Nutrient Mixture medium containing 10\% fetal bovine serum, $100 \mathrm{U} / \mathrm{ml}$ penicillin, and $100 \mu \mathrm{g} / \mathrm{ml}$ streptomycin (all from Thermo Fisher Scientific, Waltham, MA, USA). Cell culture was maintained at $37^{\circ} \mathrm{C}$ with $5 \% \mathrm{CO}_{2}$.

Vectors and transient transfection. pcDNA3.1+/C-(K)DYK-OPCML (GeneScript, Nanjing, PR China) and control vectors were included in this study. In brief, KKU-M213A $\left(7.5 \times 10^{5}\right.$ cells/well) and KKU$100\left(4 \times 10^{5}\right.$ cells/well $)$ were seeded in six-well plates and incubated at $37^{\circ} \mathrm{C}$ with $5 \% \mathrm{CO}_{2}$ overnight. At the time of transfection, 70-90\% confluent cells were then transfected with $O P C M L$ and control vectors using Lipofectamine 3000 reagent (Thermo Fisher Scientific) according to the manufacturer's protocols. After 6-h incubation, medium was replaced before being incubated at $37^{\circ} \mathrm{C}$ with $5 \% \mathrm{CO}_{2}$ for $48 \mathrm{~h}$, after which cells were harvested and used for further experiments.

Genomic DNA extraction, bisulfite treatment and methylationspecific polymerase chain reaction $(M S P)$. Genomic DNA was extracted from CCA cell lines using QIAamp DNA blood mini kit (QIAGEN, Hilden, Germany) according to the manufacturer's instructions, and subsequently modified with bisulfite using EZ DNA Methylation-GoldTM kit (Zymo Research, Irvine, CA, USA) following the manufacturer's instructions. Afterward, bisulfitemodified DNA samples were amplified by MSP with methylationspecific primer set for OPCML promoter (Table I). The hot-start PCR reaction steps were carried out as follows: An initial denaturation at $95^{\circ} \mathrm{C}$ for $5 \mathrm{~min}$, followed by 35 cycles of the following steps: $95^{\circ} \mathrm{C}$ for $30 \mathrm{~s}, 61^{\circ} \mathrm{C}$ for $30 \mathrm{~s}$, and $72^{\circ} \mathrm{C}$ for $30 \mathrm{~s}$, with a final elongation at $72^{\circ} \mathrm{C}$ for $5 \mathrm{~min}$. The amplified products were evaluated by $2 \%$ agarose gel electrophoresis.

Total RNA extraction, cDNA synthesis and reverse transcription polymerase chain reaction (RT-PCR). Total RNA was extracted from CCA cell lines using TRIzol reagent (Thermo Fisher Scientific) and was then converted to cDNA using oligo-(dT) 15 by ImProm-II ${ }^{\mathrm{TM}}$ Reverse Transcription System kit (Promega, Madison, WI, USA) according to the manufacturer's instructions. PCR primers for human $O P C M L$ and glyceraldehyde 3-phosphate dehydrogenase $(G A P D H)$ as an internal control are shown in Table I. RT-PCR was carried out as follows: An initial denaturation at $95^{\circ} \mathrm{C}$ for $5 \mathrm{~min}$, followed by 35 cycles of the following steps: $95^{\circ} \mathrm{C}$ for $30 \mathrm{~s}, 58^{\circ} \mathrm{C}$ for $30 \mathrm{~s}$, and $72^{\circ} \mathrm{C}$ for $30 \mathrm{~s}$, with a final elongation at $72^{\circ} \mathrm{C}$ for $10 \mathrm{~min}$. The amplified products were evaluated by $2 \%$ agarose gel electrophoresis.

Protein extraction, concentration determination, and western blot analysis. Cells were lysed on ice for $15 \mathrm{~min}$ in RIPA buffer (Cell Signaling Technology, Danvers, MA, USA) containing protease and phosphatase inhibitors (Roche, Basel, Switzerland), then subjected to centrifugation at $16,000 \times g$ for $20 \mathrm{~min}$ at $4^{\circ} \mathrm{C}$. After centrifugation, supernatants were collected and protein concentrations were determined by Coomassie Plus-The Better Bradford assayTM kit (Thermo Fisher Scientific). Protein lysates (20 $\mu \mathrm{g})$ were separated on $8 \%$ or $12.5 \%$ sodium dodecyl sulphatepolyacrylamide gel electrophoresis and transferred onto a polyvinylidene difluoride membrane. The membrane was then blocked with 5\% skim milk in Tris-buffered saline with $0.1 \%$ Tween 20 for $1 \mathrm{~h}$, and incubated with primary antibodies overnight at $4{ }^{\circ} \mathrm{C}$. The antibodies used were as follows: 1:1,000 rabbit monoclonal antiOPCML (Abcam, Cambridge, UK), 1:1,000 rabbit monoclonal antiAXL receptor tyrosine kinase (AXL) (C89E7), 1:500 rabbit monoclonal anti-phospho-AXL (Y779) (R\&D systems, Minneapolis, MN, USA), 1:2,000 rabbit monoclonal anti-signal transducer and activator of transcription 3 (STAT3) (79D7) (Cell Signaling Technology), 1:1,000 rabbit monoclonal anti-phospho-STAT3 (Ser727), 1:500 mouse monoclonal anti-RAS homolog family member A (RHOA), 1:500 mouse monoclonal anti-RAC family small GTPase 1 (RAC1), 1:500 mouse monoclonal anti-cell division 
cycle 42 (CDC42) (Cell Biolabs, San Diego, CA, USA), and 1:10,000 rabbit polyclonal anti-actin (Abcam). The membrane was washed three times, then incubated with horseradish peroxidaseconjugated secondary antibodies: 1:2,000 donkey anti-rabbit IgG or goat anti-mouse $\operatorname{IgG}($ Abcam) for $1 \mathrm{~h}$. After washing three times, proteins were detected by ECL ${ }^{\mathrm{TM}}$ reagents (GE Healthcare, Chicago, IL, USA). The protein images were analyzed by Amersham Imager 600 (GE Healthcare), and band intensities were quantified by Image J software (U. S. National Institutes of Health, Bethesda, MD, USA).

Proliferation assay. Cell proliferation was performed using CellTiter 96® AQueous One Solution Cell Proliferation Assay (Promega). Transfected KKU-M213A ( $5 \times 10^{3}$ cells $)$ and KKU-100 $\left(2 \times 10^{3}\right.$ cells $)$ in $100 \mu \mathrm{l}$ of complete medium were seeded in a 96-well plate in triplicates, and baseline readings were taken on the day of seeding as soon as cells were attached (15). At baseline and each time-point (day 0-4 for KKU-M213A and day 0-6 for KKU-100), $20 \mu \mathrm{l}$ of 3(4,5-dimethylthiazol-2-yl)-5-(3-carboxymethoxyphenyl)-2-(4sulfophenyl)- $2 \mathrm{H}$-tetrazolium solution (MTS) was added to each well and plates were incubated for $3 \mathrm{~h}$ before absorbance was measured at $490 \mathrm{~nm}$ using a RT-2100C Microplate Reader (Rayto Life and Analytical Sciences, Shenzhen, PR China).

Migration and invasion assays. Cell migration and invasion assays were performed using Transwell ${ }^{\circledR}$ with an $8.0 \mu \mathrm{m}$ Pore PET Membrane Insert with and without Matrigel (Corning Incorporated, Corning, NY, USA). Briefly, transfected KKU-M213A ( $4 \times 10^{4}$ cells) and KKU-100 ( $3 \times 10^{4}$ cells) in $300 \mu \mathrm{l}$ of serum-free medium were seeded into the upper chamber in duplicate and $750 \mu \mathrm{l}$ of complete medium was placed in the lower chamber. After $18 \mathrm{~h}$ incubation for KKU-M213A and $48 \mathrm{~h}$ for KKU-100, non-migrating or noninvading cells residing at the upper filter were removed. Migrating or invading cells that were attached to the underside of the filter were fixed with $100 \%$ ice-cold methanol and stained by $2 \%$ crystal violet in $2 \%$ ethanol at room temperature for $15 \mathrm{~min}$. The number of migrating or invading cells was quantified by counting under light microscope. The mean value of five fields at $\times 100$ magnification was calculated.

Apoptosis assay. Cell apoptosis was executed by Alexa Fluor ${ }^{\circledR} 488$ annexin V/Dead Cell Apoptosis kit (Thermo Fisher Scientific). In brief, transfected cells were harvested and washed twice with ice-cold phosphate-buffered saline. Cells were then resuspended in $1 \mathrm{x}$ annexin binding buffer, and stained with $5 \mu \mathrm{l}$ of annexin $\mathrm{V}$ and $1 \mu \mathrm{l}$ of 100 $\mu \mathrm{g} / \mathrm{ml}$ propidium iodide for $15 \mathrm{~min}$ at room temperature in the dark. Samples prepared in duplicate were measured by Becton Dickinson flow cytometer (BD Biosciences, Franklin Lakes, NJ, USA). The data were analyzed by BD FACSDiva software (BD Biosciences).

Statistical analysis. SPSS version 25 software (IBM, Armonk, NY, USA) was used for statistical analyses. Values are presented as the mean \pm standard deviation (SD) and significance was analyzed by independent-samples $t$-test. A value of $p<0.05$ was considered statistically significant.

\section{Results}

OPCML is epigenetically silent by promoter hypermethylation in all CCA cell lines. We initially determined the expression of mRNA and protein of OPCML

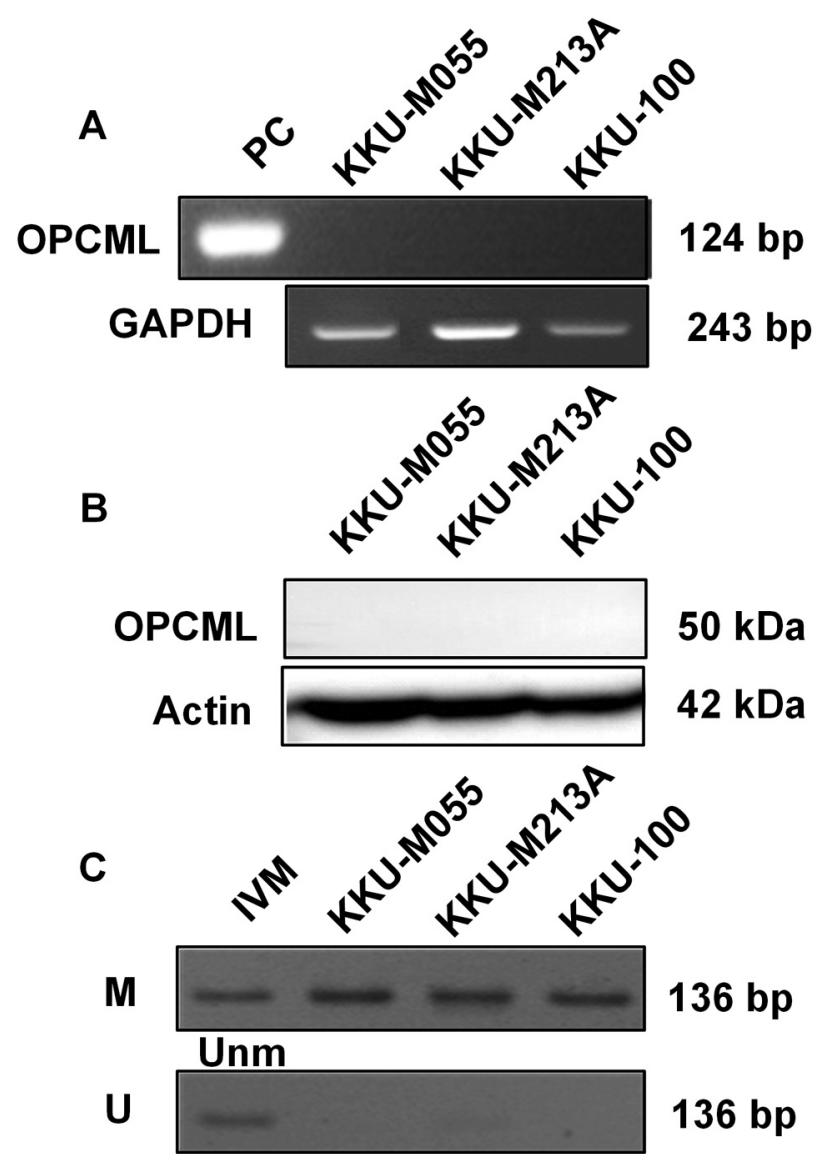

Figure 1. Loss of opioid binding protein/cell adhesion molecule like $(O P C M L)$ expression is regulated by promoter methylation in all cholangiocarcinoma (CCA) cell lines. Neither the expression of $m R N A$ (A) nor protein $(B)$ was detected in CCA cell lines while DNA methylation of the OPCML promoter was observed in all (C). IVM: In vitro methylation; M: methylated; PC: positive control; U/Unm: unmethylated.

in CCA cell lines using RT-PCR and western blot analysis, respectively. Neither mRNA nor protein expression of $O P C M L$ was observed in any of the three CCA cell lines (Figure 1A and B). The methylation status of $O P C M L$ promoter was further investigated in CCA cell lines using MSP. As shown in Figure 1C, all three CCA cell lines were methylated at the $O P C M L$ promoter, indicating that DNA methylation regulated OPCML expression in CCA.

Overexpression of OPCML in CCA cell lines after transient transfection. To investigate the biological functions of OPCML in CCA, pcDNA3.1 $/$ C-(K)DYK-OPCML was transiently transfected into KKU-M213A and KKU-100 cells. As shown by RT-PCR and western blot, OPCML was significantly overexpressed in KKU-M213A and KKU-100 

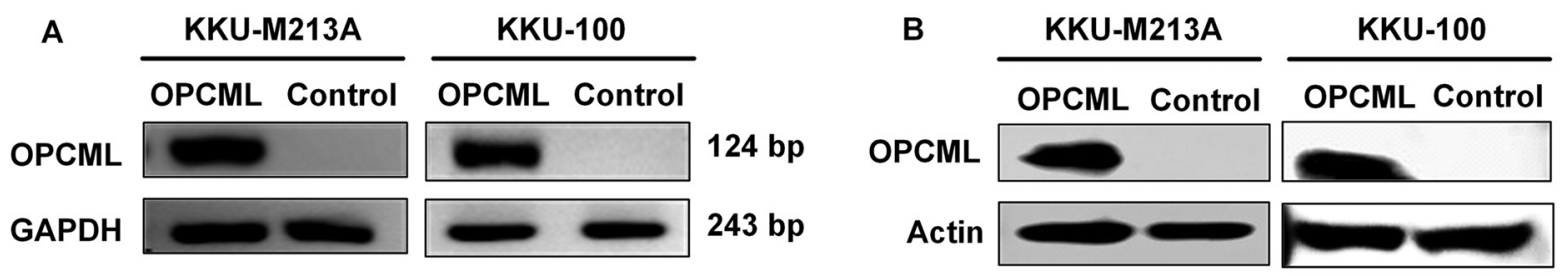

$50 \mathrm{kDa}$

Figure 2. Opioid binding protein/cell adhesion molecule like (OPCML) was significantly overexpressed in representative cholangiocarcinoma cell lines after transient transfection. Expression of OPCML $m R N A(A)$ and protein $(B)$ in KKU-M213A and KKU-100 cells after transfection with OPCML plasmid for $48 \mathrm{~h}$.

A

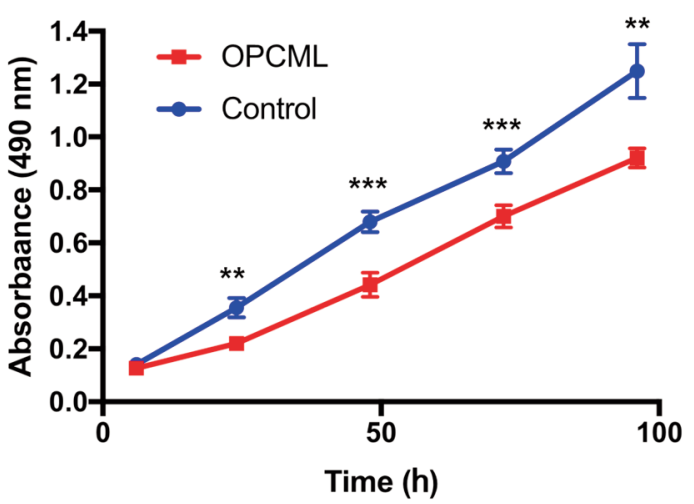

KKU-100

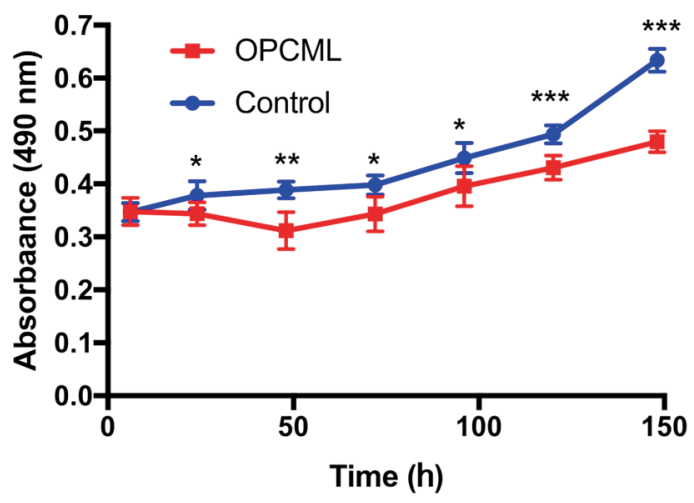

B OPCML

Control
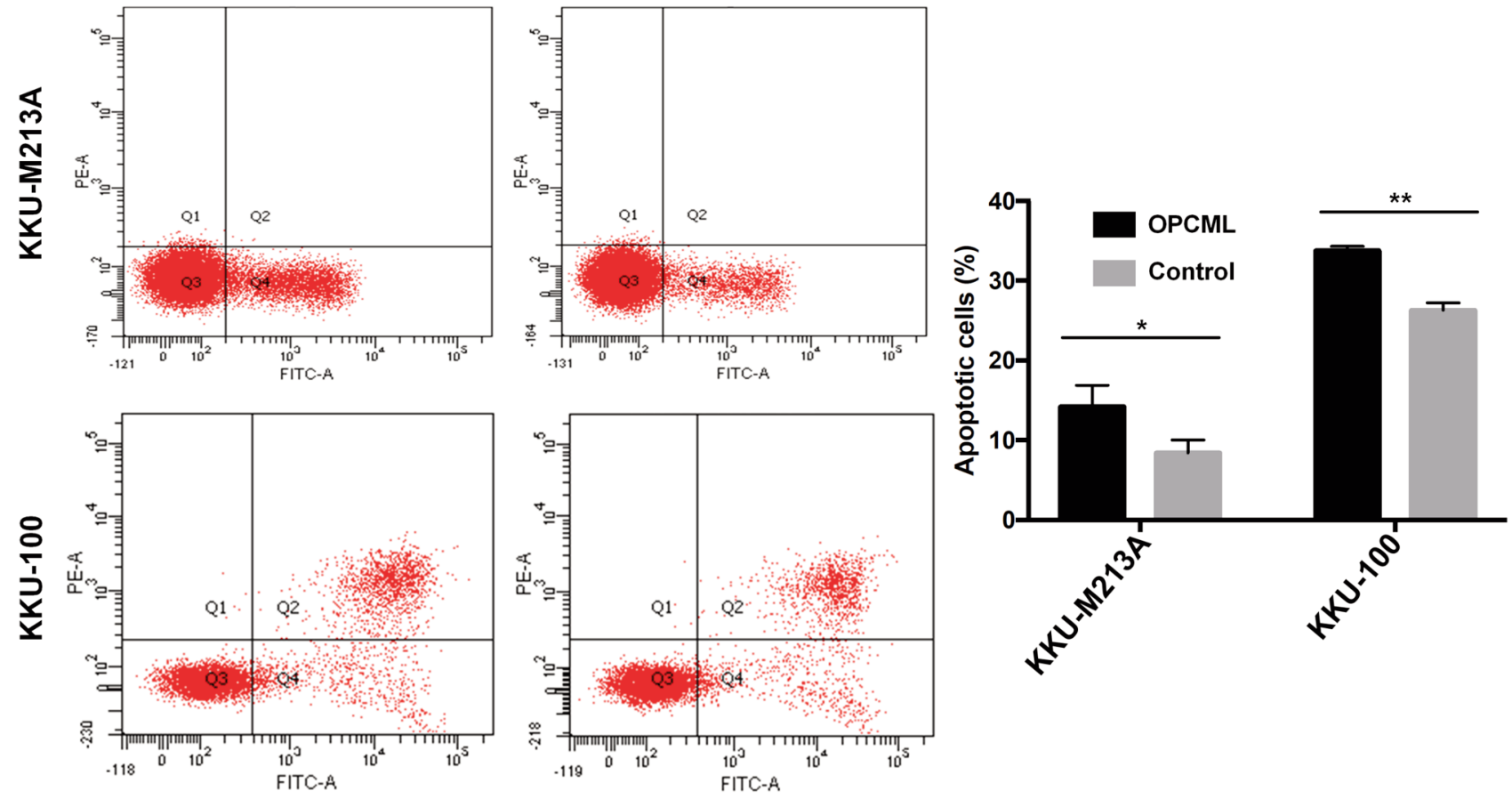

Figure 3. Opioid binding protein/cell adhesion molecule like (OPCML) diminished cholangiocarcinoma cell proliferation by inducing apoptosis. A: The effect of forced expression of OPCML on cell proliferation as shown by 3-(4,5-dimethylthiazol-2-yl)-5-(3-carboxymethoxyphenyl)-2-(4-sulfophenyl)-2H-tetrazolium (MTS) assay in KKU-M213A and KKU-100 cells. B: Representative cytograms and quantification of KKU-M213A and KKU-100 cells undergoing apoptosis after transfection with OPCML compared to control vectors. Values are expressed as mean $\pm S D$ from independent experiments running in triplicate (MTS assay) or duplicate (flow cytometry). Statistically significantly different compared to control vector at: ${ }^{*} p<0.05$, ** $p<0.01$ and *** $p<0.001$. 
A

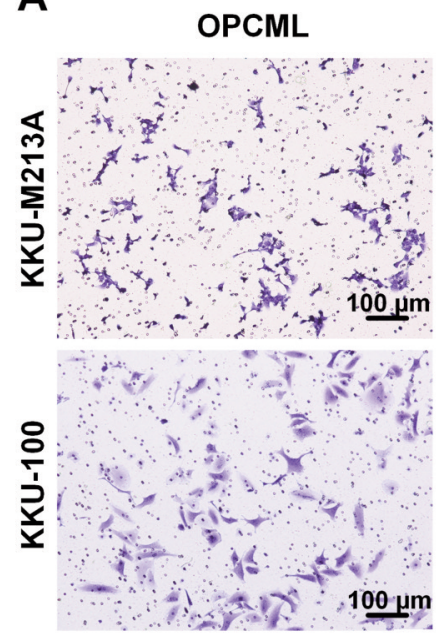

Control

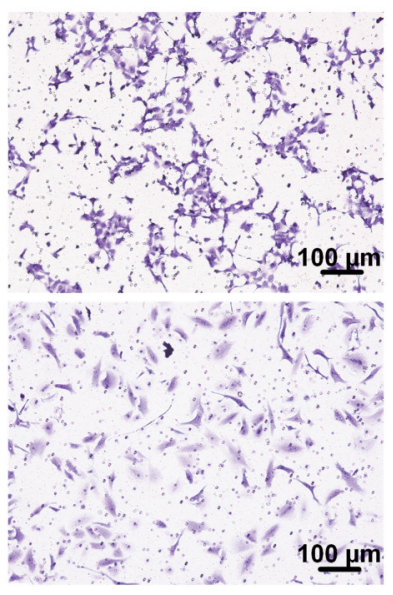

B
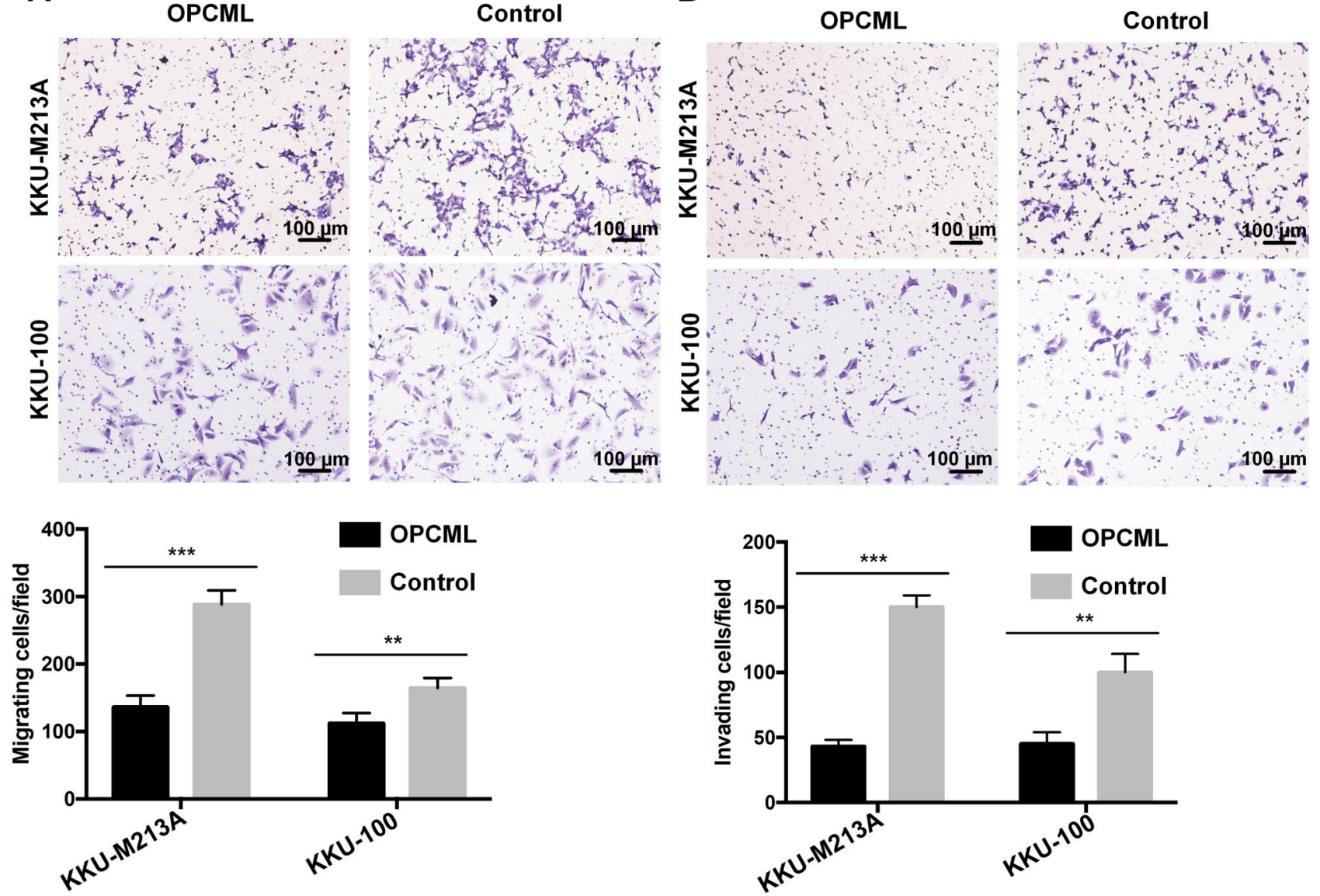

Figure 4. Opioid binding protein/cell adhesion molecule like (OPCML) suppressed migration and invasion of cholangiocarcinoma cell lines. Representative results showing the effect of forced expression of OPCML on cell migration (A) and invasion (B) as shown by transwell assay. The migrating and invading cells were counted under light microscopy with an objective lens of 10x. Five randomly selected fields for each membrane filter were counted. Values are expressed as the mean $\pm S D$ from independent experiments running in duplicate. Statistically significantly different compared to control vector at: $* * p<0.01$ and $* * * p<0.001$.

cells after transient transfection with OPCML plasmid compared to control vector (Figure 2).

Ectopic OPCML expression suppresses cell proliferation by inducing apoptosis of CCA cells. We assessed the effect of ectopic OPCML expression on the proliferation of CCA cells by carrying out MTS proliferation assay. We found that ectopic OPCML expression significantly reduced the viability of KKU-M213A on days 1-4 (Figure 3A, left panel) and of KKU-100 on days 1-6 (Figure 3A, right panel), indicating the anti-proliferative effect of OPCML on CCA cells. Furthermore, we investigated whether OPCML inhibited CCA cell proliferation by inducing apoptosis. Annexin V-fluorescein isothiocyanate/propidium iodide flow cytometry was used to detect the effect of ectopic OPCML expression on apoptosis of KKU-M213A and KKU-100 cells. We found that OPCML increased the populations of both early and late apoptotic cells from $8.4 \%$ to $14.2 \%$ $(p<0.05)$ in KKU-M213A cells transfected with OPCML, when compared to control vector. Similar results were observed in OPCML-transfected KKU-100 cells, with a significant induction of the apoptotic cell population from $26.3 \%$ to $33.8 \% \quad(p<0.01)$, when compared to cells transfected with control vector (Figure 3B). These data indicated that OPCML inhibited proliferation of CCA cells by inducing cell apoptosis.

OPCML inhibits migration and invasion of CCA cells. To further explore the effect of OPCML on the migration and invasion of CCA cells, we performed transwell assays with and without Matrigel-coated chambers. The results showed that fewer OPCML-transfected KKU-M213A and KKU-100 
cells migrated to the lower chamber than those transfected with control vector $(p<0.01$, Figure $4 \mathrm{~A})$. In addition, a similar result was also observed in the cell invasion assay $(p<0.01$, Figure 4B). Our findings indicated that OPCML suppressed migration and invasion by CCA cells.

OPCML expression is associated with AXL/STAT3 inactivation and down-regulation of Rho GTPases in CCA cells. We further sought the OPCML-mediated signaling pathways. To address whether OPCML interacted with prometastatic receptor tyrosine kinase, AXL and inhibited proliferation of CCA, we assessed the phosphorylation status of AXL and its downstream protein, STAT3 after OPCML overexpression. In the absence of OPCML, AXL and STAT3 were activated in both KKU-M213A and KKU-100 cells, whereas the levels of phosphorylated AXL and STAT3 markedly declined after ectopic OPCML expression (Figure 5A). We next investigated whether the effects of OPCML on migration and invasion were related to Rho GTPase expression. After 48-h transfection with OPCML plasmid vector, expression of Rho GTPases RHOA, RAC1, and CDC42 was significantly reduced in both KKU-M213A and KKU-100 cells, compared to the controls (Figure 5B). Activation of Rho GTPases was also determined in CCA cell lysates using pull-down assay. However, Rho GTPase activation was not observed in CCA cell lines, neither in the absence nor presence of OPCML. Overall, our findings suggest that OPCML may regulate CCA cell proliferation through the inhibition of AXL/STAT3 activation, and perhaps control the migration and invasion of CCA cells, at least in part, via down-regulation of Rho GTPases (Figure 6).

\section{Discussion}

OPCML gene is located on chromosome 11q25 and was initially identified as a candidate tumor-suppressor gene in epithelial ovarian cancer, in which it is frequently epigenetically inactivated (11). Further studies later illustrated the down-regulation or silencing of OPCML due to its promoter methylation in various primary tumor types and cancer cell lines but not in non-cancer cell lines, suggesting its broad tumor suppressor role for multiple tumor types (16). In addition, previous studies demonstrated low expression of OPCML to be associated with the carcinogenesis of many cancer types $(6,8,9,12,17-19)$. In the current study, we showed the loss of mRNA and protein expression, and promoter hypermethylation of OPCML in CCA cell lines. Sriraksa et al. demonstrated the high methylation frequency $(72.5 \%)$ for $O P C M L$ in primary CCA, in which low protein expression was found in $88 \%$ of $O P C M L$-hypermethylated CCA (5). The data from primary CCA and cell lines indicate the expression of $O P C M L$ is epigenetically regulated by DNA methylation. Moreover, methylation of $O P C M L$ was found

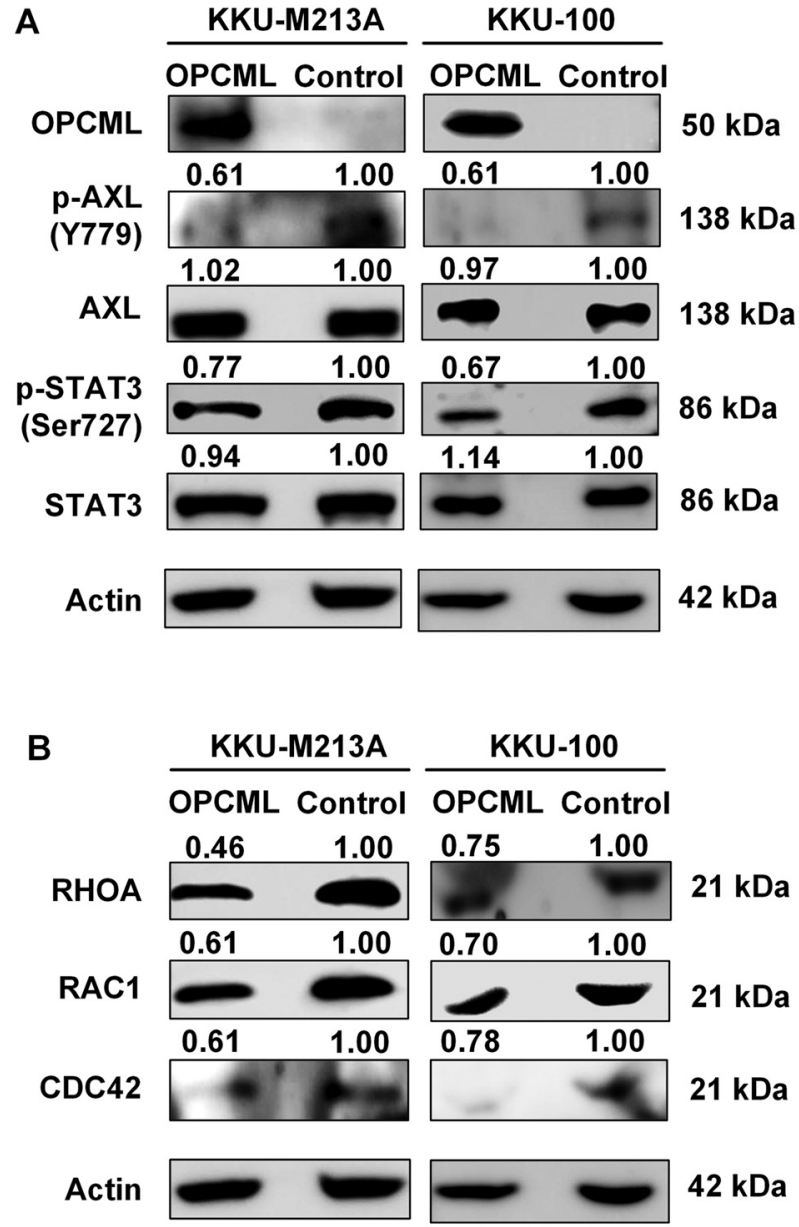

Figure 5. Opioid binding protein/cell adhesion molecule like (OPCML)related signaling component proteins as revealed by western blot analysis in cholangiocarcinoma cells. A: The levels of phosphorylated $A X L$ receptor tyrosine kinase $(A X L) /$ signal transducer and activator of transcription 3(STAT3) signaling pathway proteins under forced expression of OPCML. B: Expression of Rho GTPases; ras homolog family member A (RHOA), Rac family small GTPase 1 (RAC1) and cell division cycle 42 (CDC42). The band intensity of each protein was normalized to that of the internal control, actin. The level of the phosphorylated form was then normalized to its total form. The numbers represented the fold change from the respective control group.

more frequently in less differentiated than in welldifferentiated CCA, supporting its role in tumor progression (5). A previous study in CCA illustrated that less differentiated tumors conferred a poorer outcome and high incidence of metastases than well differentiated ones (20).

To address the roles of OPCML in CCA progression, CCA cell lines KKU-M213A and KKU-100 were transfected with $O P C M L$ plasmid vector. As a result, overexpression of $O P C M L$ inhibited proliferation of CCA via induction of apoptosis. Previous studies also showed that ectopic OPCML 


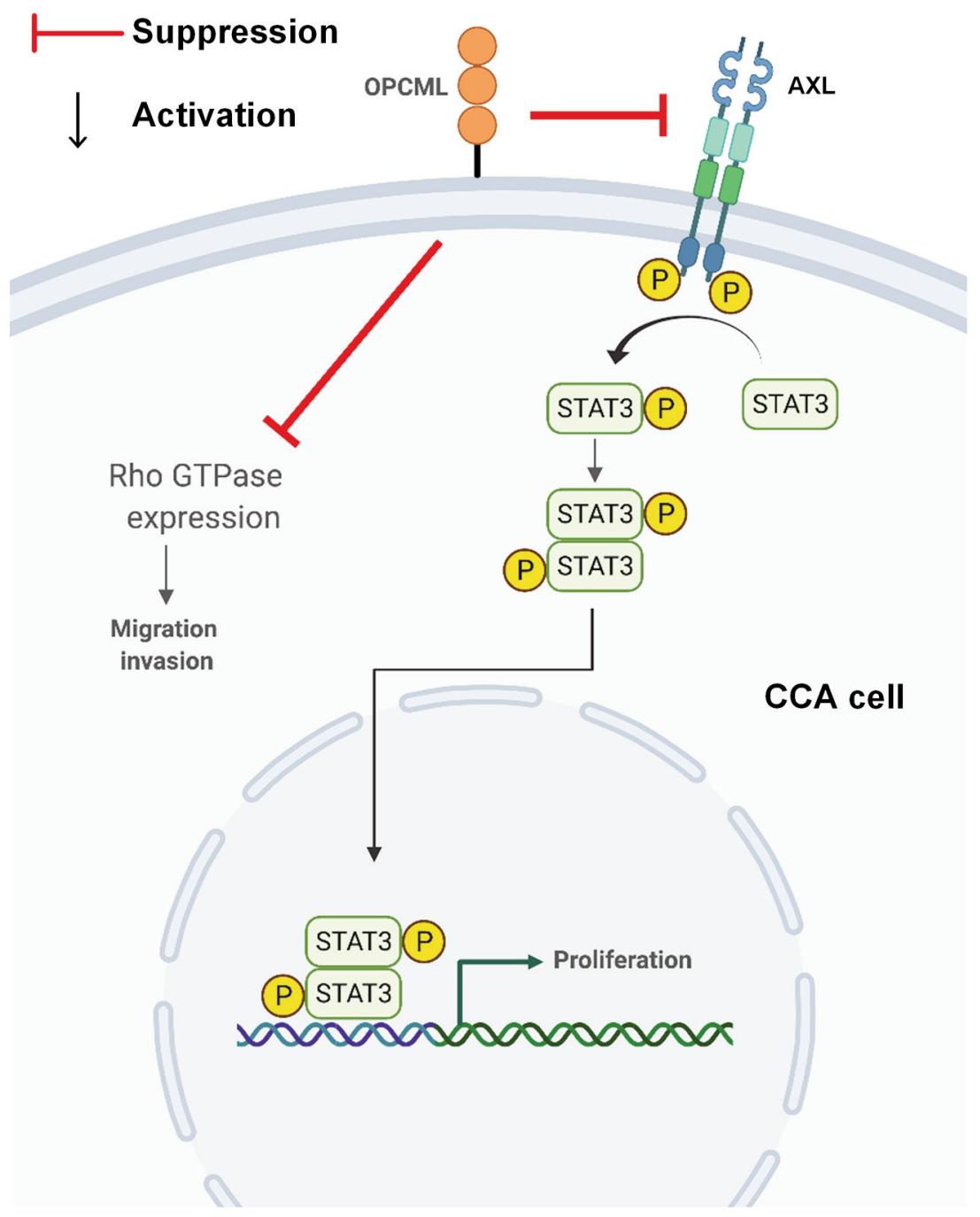

Figure 6. Schematic representation of opioid binding protein/cell adhesion molecule like (OPCML)-mediated signaling pathways in cholangiocarcinoma (CCA) cells. OPCML interferes with AXL receptor tyrosine kinase (AXL) homodimerization and phosphorylation, resulting in reduced phosphorylation of signal transducer and activator of transcription 3 (STAT3), which is an important transcription factor in activating proliferation-related genes. Moreover, OPCML can also reduce expression of Rho GTPases, leading to the suppression of CCA cell migration and invasion.

expression inhibited the proliferation of gastric and breast cancer cells $(12,13)$, in which OPCML also activated apoptosis of gastric cancer cells (12). Metastasis is a key driver of tumor progression that involves cell migration and invasion. We found that ectopic expression of OPCML reduced migration and invasion of CCA cells. The effect of OPCML on the suppression of cell migration and invasion was also reported in breast and ovarian cancer cells $(13,14)$. Moreover, Li et al. found that OPCML induced the reversal of epithelial-mesenchymal transition, which was associated with migration and invasion of colorectal cancer cells (10). The data from our and previous studies indicate a tumor- suppressive role of OPCML whose loss of its expression can lead to cancer progression.

The molecular mechanism underlying OPCML repression of cell proliferation by inducing apoptosis was investigated. Our study demonstrated that the activation of receptor tyrosine kinase, phospho-AXL was reduced in CCA cell lines after ectopic expression of $O P C M L$. Similarly, the activation of its downstream target, phospho-STAT3 was also reduced. AXL is one of the three members of the TYRO3 protein tyrosine kinase, AXL and MER proto-oncogene tyrosine kinase (TAM) receptor tyrosine kinase family which play critical roles in regulating cell proliferation, adhesion, and migration (21). 
Activation of AXL has been linked to tumor growth, high invasiveness and metastasis of many cancer types (22). Additionally, AXL was recently reported to be a crucial target of OPCML, resulting in the inhibition of motility and invasion of ovarian cancer cells (14). Many studies have elucidated that AXL may potentially drive cell proliferation through effector molecules in the Janus kinase/STAT signaling pathway (2326). STAT3 plays important roles in proliferation, survival, apoptosis, angiogenesis, and metastasis (27). Furthermore, the activation of STAT3 is also vital in CCA for cell growth and metastasis (28). In this study, the effect of OPCML on the expression but not activation of Rho GTPases (RHOA, RAC1 and CDC42) resulting in reduced cell migration and invasion was observed in CCA cell lines. The Rho GTPases belong to a subgroup of the Ras superfamily of 20-30 kDa GTP-binding proteins (29). They promote many cellular processes including actin organization, and regulation of gene expression and cell migration (30). Alterations of expression levels or activity of Rho GTPases have been reported in many cancer types. Rho GTPases are often up-regulated in human cancer, RHOA has particularly been found to be overexpressed in testicular cancer and esophageal squamous cell carcinoma $(31,32)$. In addition, RAC1 has been shown to be up-regulated in testicular, breast, prostate, gastric and lung tumors (31, 33-36). CDC42 is also overexpressed in testicular and breast cancer $(31,33)$, non-small cell lung carcinoma (37) and colorectal adenocarcinoma (38). Moreover, many studies illustrated a crucial role of Rho GTPases in the progression and metastasis of various human cancer types $(29,30,38-40)$. The mechanism by which OPCML regulates the expression of Rho GTPases in CCA requires further investigation.

Taken together, our findings suggest that OPCML plays an important role as a tumor suppressor by regulating AXL, in which its inactivation by promoter hypermethylation results in the activation of STAT3 and up-regulation of Rho GTPase signaling pathways, leading to the progression of CCA. In conclusion, our study confirmed that OPCML was epigenetically silenced in CCA. Overexpression of OPCML suppressed CCA cell proliferation, migration, and invasion, suggesting that OPCML exerts its suppressor activity at least in part through AXL/STAT3 and Rho GTPase signaling pathways. To our knowledge, this is the first time that the mechanisms related to antitumor effects of OPCML in CCA were unraveled.

\section{Conflicts of Interest}

The Authors declare no conflicts of interest.

\section{Authors' Contributions}

R. Khamko: Conceptualization, methodology, formal analysis, investigation, data curation, writing - original draft, visualization and project administration. J. Daduang: Conceptualization, methodology and validation. C. Settasatian: Conceptualization, methodology and validation. T. Limpaiboon: Conceptualization, methodology, validation, resources, writing - review and editing, supervision and funding acquisition.

\section{Acknowledgements}

This work was financially supported by the Thailand Science Research and Innovation (TSRI) through the Royal Golden Jubilee Ph.D. Program (grant no. PHD/0015/2557 to R. Khamko) and Grant-in-aid from KKU Research Funds and the Centre for Research and Development of Medical Diagnostic Laboratories, Faculty of Associated Medical Sciences, Khon Kaen University, Thailand. We express our appreciation to the Cholangiocarcinoma Research Institute, Khon Kaen University, Khon Kaen, Thailand for kindly providing CCA cell lines.

\section{References}

1 Kamsa-ard S, Kamsa-ard S, Luvira V, Suwanrungruang K, Vatanasapt $\mathrm{P}$ and Wiangnon $\mathrm{S}$ : Risk factors for cholangiocarcinoma in Thailand: A systematic review and meta-analysis. Asian Pac J Cancer Prev 19(3): 605-614, 2018. PMID: 29579789. DOI: 10.22034/APJCP.2018.19.3.605

2 Khan AS and Dageforde LA: Cholangiocarcinoma. Surg Clin North Am 99(2): 315-335, 2019. PMID: 30846037. DOI: 10.1016/j.suc.2018.12.004

3 Banales JM, Cardinale V, Carpino G, Marzioni M, Andersen JB, Invernizzi P, Lind GE, Folseraas T, Forbes SJ, Fouassier L, Geier A, Calvisi DF, Mertens JC, Trauner M, Benedetti A, Maroni L, Vaquero J, Macias RI, Raggi C, Perugorria MJ, Gaudio E, Boberg KM, Marin JJ and Alvaro D: Expert consensus document: Cholangiocarcinoma: current knowledge and future perspectives consensus statement from the European Network for the Study of Cholangiocarcinoma (ENS-CCA). Nat Rev Gastroenterol Hepatol 13(5): 261-280, 2016. PMID: 27095655. DOI: $10.1038 /$ nrgastro.2016.51

4 Macias RIR, Banales JM, Sangro B, Muntané J, Avila MA, Lozano E, Perugorria MJ, Padillo FJ, Bujanda L and Marin JJG: The search for novel diagnostic and prognostic biomarkers in cholangiocarcinoma. Biochim Biophys Acta Mol Basis Dis 1864(4 Pt B): 1468-1477, 2018. PMID: 28782657. DOI: 10.1016/j.bbadis.2017.08.002

5 Sriraksa R, Zeller C, El-Bahrawy MA, Dai W, Daduang J, Jearanaikoon P, Chau-In S, Brown R and Limpaiboon T: CpGisland methylation study of liver fluke-related cholangiocarcinoma. Br J Cancer 104(8): 1313-1318, 2011. PMID: 21448164. DOI: 10.1038/bjc.2011.102

6 Amornpisutt R, Proungvitaya S, Jearanaikoon P and Limpaiboon T: DNA methylation level of OPCML and SFRP1: a potential diagnostic biomarker of cholangiocarcinoma. Tumour Biol 36(7): 4973-4978, 2015. PMID: 25652468. DOI: 10.1007/s13277-0153147-2

7 McKie AB, Vaughan S, Zanini E, Okon IS, Louis L, de Sousa C, Greene MI, Wang Q, Agarwal R, Shaposhnikov D, Wong JL, Gungor H, Janczar S, El-Bahrawy M, Lam EW, Chayen NE and Gabra H: The OPCML tumor suppressor functions as a cell surface repressor-adaptor, negatively regulating receptor tyrosine 
kinases in epithelial ovarian cancer. Cancer Discov 2(2): 156-171, 2012. PMID: 22585860. DOI: 10.1158/2159-8290.CD-11-0256

8 Ye F, Zhang SF, Xie X and Lu WG: OPCML gene promoter methylation and gene expression in tumor and stroma cells of invasive cervical carcinoma. Cancer Invest 26(6): 569-574, 2008. PMID: 18584347. DOI: 10.1080/07357900701837044

9 Duarte-Pereira S, Paiva F, Costa VL, Ramalho-Carvalho J, Savva-Bordalo J, Rodrigues A, Ribeiro FR, Silva VM, Oliveira $\mathrm{J}$, Henrique $\mathrm{R}$ and Jerónimo C: Prognostic value of opioid binding protein/cell adhesion molecule-like promoter methylation in bladder carcinoma. Eur J Cancer 47(7): 11061114, 2011. PMID: 21273058. DOI: 10.1016/j.ejca.2010.12.025

10 Li C, Tang L, Zhao L, Li L, Xiao Q, Luo X, Peng W, Ren G, Tao Q and Xiang T: OPCML is frequently methylated in human colorectal cancer and its restored expression reverses EMT via downregulation of smad signaling. Am J Cancer Res 5(5): 16351648, 2015. PMID: 26175934.

11 Sellar GC, Watt KP, Rabiasz GJ, Stronach EA, Li L, Miller EP, Massie CE, Miller J, Contreras-Moreira B, Scott D, Brown I, Williams AR, Bates PA, Smyth JF and Gabra H: OPCML at $11 \mathrm{q} 25$ is epigenetically inactivated and has tumor-suppressor function in epithelial ovarian cancer. Nat Genet 34(3): 337-343, 2003. PMID: 12819783. DOI: $10.1038 / n g 1183$

12 Xing X, Cai W, Ma S, Wang Y, Shi H, Li M, Jiao J, Yang Y, Liu $\mathrm{L}$, Zhang $\mathrm{X}$ and Chen $\mathrm{M}$ : Down-regulated expression of OPCML predicts an unfavorable prognosis and promotes disease progression in human gastric cancer. BMC Cancer 17(1): 268, 2017. PMID: 28407749. DOI: 10.1186/s12885-017-3203-y

13 Lian B, Li H, Liu Y, Chai D, Gao Y, Zhang Y, Zhou J and Li J: Expression and promoter methylation status of OPCML and its functions in the inhibition of cell proliferation, migration, and invasion in breast cancer. Breast Cancer 28(2): 448-458, 2021. PMID: 33108608. DOI: 10.1007/s12282-020-01179-9

14 Antony J, Zanini E, Kelly Z, Tan TZ, Karali E, Alomary M, Jung Y, Nixon K, Cunnea P, Fotopoulou C, Paterson A, Roy-Nawathe S, Mills GB, Huang RY, Thiery JP, Gabra H and Recchi C: The tumour suppressor OPCML promotes AXL inactivation by the phosphatase PTPRG in ovarian cancer. EMBO Rep 19(8): e45670, 2018. PMID: 29907679. DOI: 10.15252/embr.201745670

15 Birtley JR, Alomary M, Zanini E, Antony J, Maben Z, Weaver GC, Von Arx C, Mura M, Marinho AT, Lu H, Morecroft EVN, Karali E, Chayen NE, Tate EW, Jurewicz M, Stern LJ, Recchi C and Gabra $\mathrm{H}$ : Inactivating mutations and $\mathrm{X}$-ray crystal structure of the tumor suppressor OPCML reveal cancer-associated functions. Nat Commun 10(1): 3134, 2019. PMID: 31316070. DOI: $10.1038 / \mathrm{s} 41467-019-10966-8$

16 Cui Y, Ying Y, van Hasselt A, Ng KM, Yu J, Zhang Q, Jin J, Liu D, Rhim JS, Rha SY, Loyo M, Chan AT, Srivastava G, Tsao GS, Sellar GC, Sung JJ, Sidransky D and Tao Q: OPCML is a broad tumor suppressor for multiple carcinomas and lymphomas with frequently epigenetic inactivation. PLoS One 3(8): e2990, 2008. PMID: 18714356. DOI: 10.1371/journal.pone.0002990

17 Reed JE, Dunn JR, du Plessis DG, Shaw EJ, Reeves P, Gee AL, Warnke PC, Sellar GC, Moss DJ and Walker C: Expression of cellular adhesion molecule 'OPCML' is down-regulated in gliomas and other brain tumours. Neuropathol Appl Neurobiol 33(1): 77-85, 2007. PMID: 17239010. DOI: 10.1111/j.13652990.2006.00786.x

18 Zhou F, Tao G, Chen X, Xie W, Liu M and Cao X: Methylation of OPCML promoter in ovarian cancer tissues predicts poor patient survival. Clin Chem Lab Med 52(5): 735-742, 2014. PMID: 24327526. DOI: 10.1515/cclm-2013-0736

19 Wu Y, Davison J, Qu X, Morrissey C, Storer B, Brown L, Vessella $\mathrm{R}$, Nelson P and Fang M: Methylation profiling identified novel differentially methylated markers including OPCML and FLRT2 in prostate cancer. Epigenetics 11(4): 247-258, 2016. PMID: 26890304. DOI: $10.1080 / 15592294.2016 .1148867$

20 Nakajima T, Kondo Y, Miyazaki M and Okui K: A histopathologic study of 102 cases of intrahepatic cholangiocarcinoma: histologic classification and modes of spreading. Hum Pathol 19(10): 1228-1234, 1988. PMID: 2844646. DOI: 10.1016/s0046-8177(88)80156-4

21 Axelrod $\mathrm{H}$ and Pienta KJ: Axl as a mediator of cellular growth and survival. Oncotarget 5(19): 8818-8852, 2014. PMID: 25344858. DOI: $10.18632 /$ oncotarget.2422

22 Rankin EB and Giaccia AJ: The receptor tyrosine kinase AXL in cancer progression. Cancers (Basel) 8(11): 103, 2016. PMID: 27834845. DOI: $10.3390 /$ cancers 8110103

23 Dagamajalu S, Rex DAB, Palollathil A, Shetty R, Bhat G, Cheung LWT and Prasad TSK: A pathway map of AXL receptor-mediated signaling network. J Cell Commun Signal 15(1): 143-148, 2021. PMID: 32829427. DOI: 10.1007/s12079-020-00580-5

24 Zhu C, Wei Y and Wei X: AXL receptor tyrosine kinase as a promising anti-cancer approach: functions, molecular mechanisms and clinical applications. Mol Cancer 18(1): 153, 2019. PMID: 31684958. DOI: 10.1186/s12943-019-1090-3

25 Linger RM, Keating AK, Earp HS and Graham DK: TAM receptor tyrosine kinases: biologic functions, signaling, and potential therapeutic targeting in human cancer. Adv Cancer Res 100: 35-83, 2008. PMID: 18620092. DOI: 10.1016/S0065230X(08)00002-X

26 May CD, Garnett J, Ma X, Landers SM, Ingram DR, Demicco EG, Al Sannaa GA, Vu T, Han L, Zhang Y, Kivlin CM, Bolshakov S, Kalam AA, Liu J, Zhou F, Broccoli D, Wang WL, Lazar AJ, Pollock RE, Lev D and Torres KE: AXL is a potential therapeutic target in dedifferentiated and pleomorphic liposarcomas. BMC Cancer 15: 901, 2015. PMID: 26573603. DOI: $10.1186 / \mathrm{s} 12885-015-1916-3$

27 Chen H, Zhu B, Zhao L, Liu Y, Zhao F, Feng J, Jin Y, Sun J, Geng R and Wei Y: Allicin inhibits proliferation and invasion in vitro and in vivo via SHP-1-mediated STAT3 signaling in cholangiocarcinoma. Cell Physiol Biochem 47(2): 641-653, 2018. PMID: 29794468. DOI: $10.1159 / 000490019$

28 Zheng T, Hong X, Wang J, Pei T, Liang Y, Yin D, Song R, Song X, Lu Z, Qi S, Liu J, Sun B, Xie C, Pan S, Li Y, Luo X, Li S, Fang X, Bhatta N, Jiang H and Liu L: Gankyrin promotes tumor growth and metastasis through activation of IL-6/STAT3 signaling in human cholangiocarcinoma. Hepatology 59(3): 935946, 2014. PMID: 24037855. DOI: 10.1002/hep.26705

29 Van Aelst L and D'Souza-Schorey C: Rho GTPases and signaling networks. Genes Dev 11(18): 2295-2322, 1997. PMID: 9308960. DOI: $10.1101 / \mathrm{gad} .11 .18 .2295$

30 Etienne-Manneville S and Hall A: Rho GTPases in cell biology. Nature 420(6916): 629-635, 2002. PMID: 12478284. DOI: 10.1038 /nature01148

31 Kamai T, Yamanishi T, Shirataki H, Takagi K, Asami H, Ito Y and Yoshida K: Overexpression of RhoA, Rac1, and Cdc42 GTPases is associated with progression in testicular cancer. Clin Cancer Res 10(14): 4799-4805, 2004. PMID: 15269155. DOI: 10.1158/1078-0432.CCR-0436-03 
32 Faried A, Faried LS, Usman N, Kato H and Kuwano H: Clinical and prognostic significance of RhoA and RhoC gene expression in esophageal squamous cell carcinoma. Ann Surg Oncol 14(12): 3593-3601, 2007. PMID: 17896152. DOI: 10.1245/s10434-0079562-x

33 Fritz G, Brachetti C, Bahlmann F, Schmidt M and Kaina B: Rho GTPases in human breast tumours: expression and mutation analyses and correlation with clinical parameters. Br J Cancer 87(6): 635-644, 2002. PMID: 12237774. DOI: 10.1038/sj.bjc.6600510

34 Engers R, Ziegler S, Mueller M, Walter A, Willers R and Gabbert HE: Prognostic relevance of increased Rac GTPase expression in prostate carcinomas. Endocr Relat Cancer 14(2): 245-256, 2007. PMID: 17639041. DOI: 10.1677/ERC-06-0036

35 Ji J, Feng X, Shi M, Cai Q, Yu Y, Zhu Z and Zhang J: Rac1 is correlated with aggressiveness and a potential therapeutic target for gastric cancer. Int J Oncol 46(3): 1343-1353, 2015. PMID: 25585795. DOI: $10.3892 /$ ijo.2015.2836

36 Pan Y, Bi F, Liu N, Xue Y, Yao X, Zheng Y and Fan D: Expression of seven main Rho family members in gastric carcinoma. Biochem Biophys Res Commun 315(3): 686-691, 2004. PMID: 14975755. DOI: 10.1016/j.bbrc.2004.01.108

37 Liu Y, Wang Y, Zhang Y, Miao Y, Zhao Y, Zhang PX, Jiang GY, Zhang JY, Han Y, Lin XY, Yang LH, Li QC, Zhao C and Wang EH: Abnormal expression of p120-catenin, E-cadherin, and small GTPases is significantly associated with malignant phenotype of human lung cancer. Lung Cancer 63(3): 375-382, 2009. PMID: 19162367. DOI: 10.1016/j.lungcan.2008.12.012
38 Gómez Del Pulgar T, Valdés-Mora F, Bandrés E, Pérez-Palacios R, Espina C, Cejas P, García-Cabezas MA, Nistal M, Casado E, González-Barón M, García-Foncillas J and Lacal JC: Cdc42 is highly expressed in colorectal adenocarcinoma and downregulates ID4 through an epigenetic mechanism. Int J Oncol 33(1): 185-193, 2008. PMID: 18575765.

39 Wang D, Dou K, Xiang H, Song Z, Zhao Q, Chen Y and Li Y: Involvement of RhoA in progression of human hepatocellular carcinoma. J Gastroenterol Hepatol 22(11): 1916-1920, 2007. PMID: 17914970. DOI: 10.1111/j.1440-1746.2006.04534.x

40 Gómez del Pulgar T, Benitah SA, Valerón PF, Espina C and Lacal JC: Rho GTPase expression in tumourigenesis: evidence for a significant link. Bioessays 27(6): 602-613, 2005. PMID: 15892119. DOI: $10.1002 /$ bies.20238
Received August 11, 2021

Revised October 9, 2021

Accepted October 12, 2021 